\title{
Identification of an intestine-specific promoter and inducible expression of bacterial a-galactosidase in mammalian cells by a lac operon system
}

Yafeng Zhai ${ }^{\dagger}$, Gang Shu ${ }^{\dagger}$, Xiaotong Zhu, Zhiqi Zhang, Xiajing Lin, Songbo Wang, Lina Wang, Yongliang Zhang and Qingyan Jiang*

\begin{abstract}
Background: a-galactosidase has been widely used in animal husbandry to reduce anti-nutritional factors (such as a-galactoside) in feed. Intestine-specific and substrate inducible expression of a-galactosidase would be highly beneficial for transgenic animal production.

Methods: To achieve the intestine-specific and substrate inducible expression of a-galactosidase, we first identified intestine-specific promoters by comparing the transcriptional activity and tissue specificity of four intestine-specific promoters from human intestinal fatty acid binding protein, rat intestinal fatty acid binding protein, human mucin-2 and human lysozyme. We made two chimeric constructs combining the promoter and enhancer of human mucin-2, rat intestinal trefoil factor and human sucrase-isomaltase. Then a modified lac operon system was constructed to investigate the induction of a-galactosidase expression and enzyme activity by isopropyl $\beta$-D-1-thiogalactopyranoside (IPTG) and an a-galactosidase substrate, a-lactose.

We declared that the research carried out on human (Zhai Yafeng) was in compliance with the Helsinki Declaration, and experimental research on animals also followed internationally recognized guidelines.

Results: The activity of the human mucin-2 promoter was about 2 to 3 times higher than that of other intestine-specific promoters. In the lac operon system, the repressor significantly decreased $(P<0.05)$ luciferase activity by approximately 6.5 -fold and reduced the percentage of cells expressing green fluorescent protein (GFP) by approximately 2-fold. In addition, the expression level of a-galactosidase mRNA was decreased by 6-fold and a-galactosidase activity was reduced by 8-fold. In line with our expectations, IPTG and a-lactose supplementation reversed $(P<0.05)$ the inhibition and produced a 5 -fold increase of luciferase activity, an 11 -fold enhancement in the percentage of cells with GFP expression and an increase in a-galactosidase mRNA abundance (by about 5-fold) and a-galactosidase activity (by about 7-fold).
\end{abstract}

Conclusions: We have successfully constructed a high specificity inducible lac operon system in an intestine-derived cell line, which could be of great value for gene therapy applications and transgenic animal production.

Keywords: a-galactosidase, Inducible expression, Intestine-specific promoters, Lac operon

\footnotetext{
* Correspondence: qyjiang@scau.edu.cn

${ }^{\dagger}$ Equal contributors

College of Animal Science, South China Agricultural University, Guangzhou

510642, China
} 


\section{Introduction}

$\alpha$-galactosidase, an exo-glycosidase enzyme that hydrolyzes Gal glycosidic bonds, has been widely used in both medical research and animal husbandry. For example, the $\alpha$-galactosidase gene has been investigated for the gene therapy of Fabry disease, which is caused by a defect in $\alpha$-galactosidase activity [1]. In addition, $\alpha$ galactosidase has been used as a tool for changing blood type $\mathrm{B}$ to $\mathrm{O}$ because of its ability to diminish the cell membrane antigen [2]. In animal husbandry, antinutritional factors (like $\alpha$-galactoside in soybean meal) can cause flatulence and even permeability diarrhea in monogastric animals [3], while $\alpha$-galactosidase supplementation in diets can not only improve the utilization of oligosaccharides and nutrient absorption in the intestinal tract but can also improve growth performance [4-6].

Human $\alpha$-galactosidase has been used in a transgenic mouse model for Fabry disease [1,7]; however, the cytomegalovirus (CMV) promoter used in these studies demonstrated poor and nonspecific expression of $\alpha$ galactosidase in almost all tissues. Therefore, abundant expression during the embryonic stage might cause embryos to be aborted or stillborn [8].

To achieve the specific expression of an exogenous gene in the gastrointestinal tract, several promoters have been used for cell-specific gene delivery, such as the human intestinal fatty acid binding protein promoter (HIFABP) [9], the rat intestinal fatty acid binding protein promoter (RIFABP) [10], the human mucin-2 promoter (HMUC2) [11], the human lysozyme promoter (HLY) [12], the human sucrase-isomaltase enhancer (HSI) [13] and the rat intestinal trefoil factor (RITF) [14]. Although the activities of these intestine-specific promoters are known, the regulatory element that is most appropriate for directing $\alpha$-galactosidase expression in intestinal cells still required identification.

Some binary systems, such as the lac operon system [15], the tetR-based system [16], the GAL4-based system [17] and the Cre/loxP recombination system [18], have been used to turn gene expression on and off transiently or permanently. Bacterial lac operon-regulated gene expression in mammalian cells was first demonstrated by $\mathrm{Hu}$ and Davidson [19]. Cronin et al. [15] also showed that the lac operon system was functional in the mouse and could provide tight and reversible gene expression. The lac operon induction system might be the best option for inducible $\alpha$-galactosidase expression because $\alpha$-galactosidase hydrolysis of oligosaccharides or milk can produce $\alpha$-lactose, which binds to the lac repressor and facilitates positive feedback of $\alpha$-galactosidase expression.

To achieve intestine-specific and substrate inducible expression of $\alpha$-galactosidase, we first compared the activity and cell specificity of several regulatory elements associated with intestinal gene expression. Then an $\alpha-$ galactosidase inducible expression vector was constructed based on the lac operon system. Luciferase activity and $\alpha$-galactosidase activity were also investigated in response to isopropyl- $\beta$-D-thiogalactoside (IPTG) and $\alpha$-lactose to assess the construct's ability to regulate induction of target gene expression.

\section{Materials and methods \\ Plasmid construction}

Three human intestine-specific promoters, HIFABP, HMUC2 and HLY, and the HSI enhancer were amplified by PCR using human genomic DNA template. The RIFABP promoter was amplified by PCR using rat genomic intestinal DNA template. The primers used are shown in Table 1 . The 59 bp RITF enhancer was chemically synthesized. Six plasmids with four different promoters and two different enhancers were constructed using the pGL3-Basic plasmid backbone (Promega, Shang Hai, China) (Figure 1A).

To construct the lac operon, the repressor gene (LacI) was isolated from wild-type Escherichia coli, and a nuclear localization signal (NLS) was added during PCR amplification [20,21]. LacI was then cloned in a pGL3control vector (Promega, China) by replacing the firefly luciferase (luc) gene. The 116 bp operator ( $L a c O$ ) (Figure 1B) was chemically synthesized and cloned in a pGL3-Basic vector [22,23]. The reporter plasmid, pBGFP, was constructed by replacing the luc gene with green fluorescent protein (GFP) (from pshRNA-copGFP Lentivector) as a negative control.

$\alpha$-galactosidase $(\alpha-G a l)$ was obtained from a pPIC9Agil vector (a gift from Prof. Yao, Feed Research Institute Chinese Academy of Agricultural Sciences, China) and then cloned into a pHMLacO vector by replacing the luc gene. The plasmid, pHMLacO which luc gene was replaced by $\alpha$-Gal without the HMUC2 promoter was used as a negative control.

\section{Cell culture and DNA transfection}

Cells, including IPEC-1 (pigljejunum), HeLa (human/ cervical), HepG2 (human|hepatic), NIH-3T3 (mouse/ embryonic fibroblast), 293T (human/kidney) and $\mathrm{CHO}$ (hamster/ovary) were cultured in Dulbecco's modified Eagle's medium, and SW480 (human/colon) cells were cultured in Leibovitz's L-15 medium (Gibco, China) with $10 \%$ fetal bovine serum, penicillin $\mathrm{G}(100 \mathrm{U} / \mathrm{mL})$, streptomycin $(100 \mu \mathrm{g} / \mathrm{mL})$, and $2 \mathrm{mmol} / \mathrm{L} \mathrm{L}$-glutamine at $37^{\circ} \mathrm{C}$ in $5 \% \mathrm{CO}_{2} /$ air. The IPEC-1 cell line was kindly provided by Dr. Kong (Institute of Subtropical Agriculture, the Chinese Academy of Sciences) and other cell lines were obtained from the cell bank of Zhongshan Medical College. 
Table 1 Primers and regulatory element sequences used in this paper

\begin{tabular}{|c|c|c|c|}
\hline Name $^{1}$ & GenBank & Primer sequenc $\left(5^{\prime}-3^{\prime}\right)$ & Product (bp) \\
\hline \multirow[t]{2}{*}{ HMUC2 } & U67167 & S:5'-CTAGCTAGCTCCTCCCAGCGTAACGTGAGC-3' & 466 \\
\hline & & A:5'-GAAGATCTCTAGTGGCAGCCCCATGGTG-3' & \\
\hline \multirow[t]{2}{*}{ HIFABP } & NG_011444 & S:5'-CCGACGCGTGTTAGATTTATCTTCCCTTGACC-3' & 1154 \\
\hline & & A:5'-CCGCTCGAGTACCTTCCAAGTGCTGTCAAAC-3' & \\
\hline \multirow[t]{2}{*}{ RIFABP } & NW_047627 & $\mathrm{S}: 5^{\prime}$-CGACGCGTCATGCTGAATTCCTTAATTTGC-3' & 1232 \\
\hline & & A:5'-CCGCTCGAGCAGCTGTGTGTGCCTCTAGG-3' & \\
\hline \multirow[t]{2}{*}{ HLY } & NM_000239 & S:5'-CTAGCTAGCCTGTCCTCTTAGGCAGATACAGA-3' & 1186 \\
\hline & & A:5'- GAAGATCTAGAGCCTTCATGTTGACTGCTA-3' & \\
\hline \multirow[t]{2}{*}{$\mathrm{HSI}$} & X85797 & S: 5'- GGGGTACCCAATGAGTGCTATCTGTGGT-3' & 230 \\
\hline & & A: 5'-CGACGCGTAAGGAAAGCTGCTTAGGTA-3' & \\
\hline \multirow[t]{2}{*}{ Lacl } & V00294 & S: 5'-CCCAAGCTTCCGGAAGAGAGTCAATTCAG-3' & 1143 \\
\hline & & A:5'-GCTCTAGAAGTTTCGAAGGAGAAGAAGAATCCCTGCCCGCTTTCCAGTC'-3' & \\
\hline \multirow[t]{2}{*}{ GFP } & AY268072.1 & S: 5'-CCAAGCTITTGTTTCGTITTCTGTTCTGCG-3' & 763 \\
\hline & & A: 5'-GCTCTAGAGCAGCGTATCCACATAGCGTAA-3' & \\
\hline \multirow[t]{2}{*}{ a-Gal } & DQ344486 & S: 5'-CATGCCATGGGCGGATGGTACTCTCTTTG-3' & 2153 \\
\hline & & A: 5'-GCTCTAGACTATTGCTITTCCAACATCA-3' & \\
\hline RITF enhancer & & 5'-CGGGGTACCTGTTTTCCTCCCTAACCCTCTCCCCTCCCCCTCGGACTCCCACGCGTCGC-3' & 59 \\
\hline
\end{tabular}

${ }^{1} \mathrm{HMUC2}=$ human mucin-2 promoter; HIFABP = human intestinal fatty acid binding protein promoter; RIFABP = rat intestinal fatty acid binding protein promoter; $\mathrm{HLY}=$ human lysozyme promoter; $\mathrm{HSI}=$ human sucrase-isomaltase enhancer; $\mathrm{LaCl}=$ lac operon repressor; $\mathrm{GFP}=\mathrm{green}$ fluorescent protein; $\mathrm{a}-\mathrm{Gal}=\mathrm{a}-$ galactosidase; RITF = rat intestinal trefoil factor.

Transient transfections were performed using GenEs$\operatorname{cort}^{\mathrm{Tt}}$ III (Wisegen, China) with approximately $1.5 \times 10^{5}$ cells/well in 24-well dishes and $2 \mu \mathrm{g}$ of each DNA. Plasmids were purified with the E.Z.N.A ${ }^{\mathrm{TM}}$ EndoFee Plasmid Kit (Omega, China). In all cases, 200 ng of a plasmid containing the Renilla luciferase gene driven by the TK promoter (pRL-TK vector, Promega, China) was included in the assay to monitor transfection efficiency. After $48 \mathrm{~h}$, cells were measured for luciferase activity. For induction experiments, both IPTG (Sigma, China) and $\alpha$-lactose (Sigma, China) were prepared as 100 $\mathrm{mmol} / \mathrm{L}$ stock solutions in Dulbecco's modified phosphate-buffered saline without $\mathrm{Ca}^{2+}$ and $\mathrm{Mg}^{2+}, \mathrm{pH}$ 7.4 (PBS-).

For the transfection of a single plasmid, $4 \mu \mathrm{g}$ of plasmid DNA was mixed with $10 \mu \mathrm{L}$ of GenEscort ${ }^{\mathrm{Tx}}$ III in PBS(-), and made up to a total of $200 \mu \mathrm{L}$ with OptiMEM (Gibco, China). For co-transfection, two plasmids (3 $\mu$ g each) were mixed with $14 \mu \mathrm{L}$ of GenEscort ${ }^{\mathrm{m}} \mathrm{III}$ in Opti-MEM to a total of $200 \mu \mathrm{L}$. These DNA/liposome complexes were added to approximately $5 \times 10^{5}$ cells/well in 6-well dishes and incubated for $48 \mathrm{~h}$ at $37^{\circ} \mathrm{C}$. The DNA/liposome complexes were added to SW480 cells cultured in $25 \mathrm{~cm}^{2}$ cell culture bottles and incubated for $96 \mathrm{~h}$. For RNA extraction and $\alpha$-galactosidase activity assays, medium was replaced by PBS prior to processing, while for induction experiments, medium was replaced with fresh media containing $2.5 \mathrm{mmol} / \mathrm{L}$ IPTG or $5 \mathrm{mmol} / \mathrm{L} \alpha$-lactose. The cells were induced for $12 \mathrm{~h}$ before being observed for fluorescence and harvesting for FACS.

\section{Fluorescence detection}

Cells were observed using a Leica DMI 4000B fluorescence microscope (Leica) with DM505 filters (BP460-490 and BA510IF) for GFP monitoring. Microphotographs were taken using a digital camera (FUJIX HC-300/OL, FujiFilm) attached to the fluorescence microscope.

\section{Fluorescence Activated Cell Sorting (FACS) analysis}

Forty-eight hours after transfection, cells were washed twice with $\mathrm{PBS}(-)$ and dissociated with trypsin/EDTA. After centrifugation at $1,000 \mathrm{rpm}$ for $5 \mathrm{~min}$ at $4^{\circ} \mathrm{C}$, cells were resuspended at $1 \times 10^{6}$ cells $/ \mathrm{mL}$ in $1 \mathrm{x}$ Assay Buffer (KeyGEN, China) and stored on ice for a maximum of $1 \mathrm{~h}$ before analysis. Then $5 \mu \mathrm{L}$ 7-AAD (KeyGEN, China) was added immediately prior to flow cytometry. Acquisition was performed on a FACSCalibur system (BD Bioscience), and samples were analyzed using Cell Quest Pro software (BD Bioscience). In each experiment, 10,000 counts were evaluated. Cells exhibiting 7-AAD uptake were considered dead and excluded from the analysis of GFP-positive cells by gating on 7-AAD negative cells. 


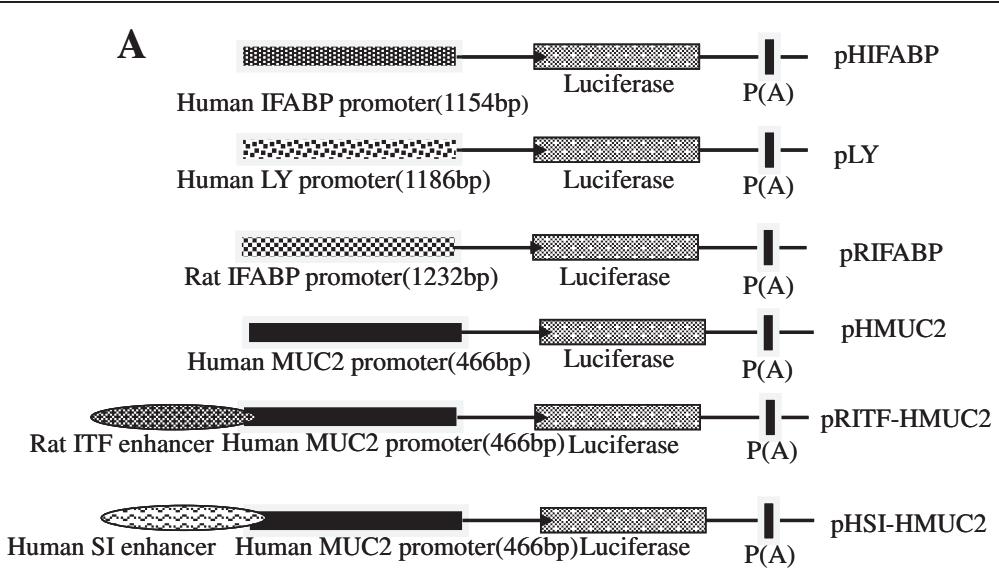

B

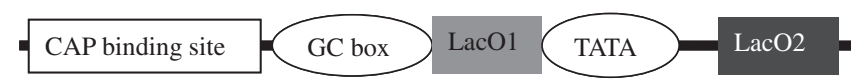

Figure 1 Schematic structure of the intestine-specific promoters and operator. (A) Promoter/enhancer fusion constructs. Four intestinespecific promoters were cloned into a pGL3-Basic vector to drive luciferase expression. In addition, the human mucin-2 promoter (HMUC2) sequence was fused to the human sucrase-isomaltase (HSI) and rat intestinal trefoil factor (RITF) regions to drive luciferase expression.

(B) Schematic structure of the synthetic 116 bp operator, which consists of the two important components: LacO1 and LacO2.

\section{Luciferase assay}

Luciferase activity was assayed $48 \mathrm{~h}$ after transfection using a Dual-Luciferase Reporter Assay System kit (Promega, China). Cells were washed with PBS(-) and harvested in $200 \mu \mathrm{L}$ of Passive Lysis Buffer (PLB, Promega, China). After centrifugation at 12,000 rpm for $5 \mathrm{~min}$ at $4^{\circ} \mathrm{C}$, the supernatant $(100 \mu \mathrm{L})$ was transferred to a fresh $1.5 \mathrm{~mL}$ Eppendorf tube. Firefly and Renilla luciferase activity was measured in a Synergy Mx MonochromatorBased Multi-Mode Microplate Reader (BioTek, China). Firefly luciferase activity was measured for $10 \mathrm{sec}$ following a $2 \mathrm{sec}$ delay after the addition of the lysate $(20 \mu \mathrm{L})$ to $100 \mu \mathrm{L}$ of LAR II (Promega, China), and Renilla luciferase activity was measured for $10 \mathrm{sec}$ following a $2 \mathrm{sec}$ delay after the addition of $100 \mu \mathrm{L}$ Stop \& Glo ${ }^{\circledR}$ Reagent. Data are presented as the relative activity of Firefly luciferase to Renilla luciferase to normalize for transfection efficiency.

\section{Determination of a-galactosidase mRNA levels}

Total RNA was extracted using Trizol reagent according to the manufacturer's recommendations (Invitrogen, China). First-strand cDNA synthesis was performed using Oligo- $(\mathrm{dT})_{18}$ (Invitrogen, China). The reaction mix was subjected to RT-PCR to detect levels of $\alpha-G a l$ and human $\beta$-actin mRNA. Human $\beta$-actin was used as an internal control. The relative mRNA levels were determined and analyzed using the ABI Prism 7000 Sequence Detection System (Applied Biosystems). Transfection and assessment experiments were repeated three times to analyze relative gene expression, and each sample was tested in triplicate.

\section{a-galactosidase activity assay}

Enzyme activity was assayed in a reaction mixture containing $0.1 \mathrm{~mL}$ of McIlvaine buffer (Phosphate and citric acid , $100 \mathrm{mmol} / \mathrm{L}, \mathrm{pH}=4.8$ ) and $0.5 \mathrm{~mL}$ of $20 \mathrm{mmol} / \mathrm{L}$ p-nitrophenyl- $\alpha$-D-galactopyranoside (pNPG) substrate (den Herder et al., 1992) [24]. The reaction mixture was pre-incubated at $37^{\circ} \mathrm{C}$ for $5 \mathrm{~min}$ before adding $0.2 \mathrm{~mL}$ of enzyme solution (cell lysate). After $5 \mathrm{~min}$, the reaction was stopped by adding $1.5 \mathrm{~mL}$ of $0.1 \mathrm{~mol} / \mathrm{L} \mathrm{Na}_{2} \mathrm{CO}_{3}$ solution. The released $\mathrm{p}$-nitrophenol was determined spectrophotometrically at $405 \mathrm{~nm}$ using a calibration curve prepared with p-nitrophenol under the same conditions. One unit of $\alpha$-galactosidase activity was defined as the amount of enzyme liberating $1 \mu \mathrm{mol}$ p-nitrophenol in $1 \mathrm{~min}$ under the assay conditions. The amount of protein was determined using a Bio-Rad dye-binding assay (Bio-Rad Laboratories) and bovine serum albumin as a standard.

\section{Statistical analysis}

All values are expressed as means \pm SEM. The statistical significance of the differences among groups was analyzed by one-way ANOVA. Multiple comparisons among means were conducted using Tukey's procedure when significant difference was identified. Difference was regarded as significant when $\mathrm{P}<0.05$. All statistical analyses were performed using the SPSS 17.0 software package. 


\section{Results}

Construction of reporter plasmids containing intestinal promoters: Comparative In Vitro study

Figure 2A shows that the HMUC2 promoter has the highest activity among the intestine-specific promoters tested, which was about 2 to 3 times higher than that of the other three promoters $(P<0.05)$. RITF and HSI were unable to enhance the promoter activity of HMUC2, and surprisingly decreased $(P<0.05)$ the activity of HMUC2 3-fold and 30-fold, respectively (Figure 2B). Transfection of SW480, 293T, CHO, NIH-3T3, IPEC-1, HeLa and HepG2 cells showed that the HMUC2 promoter demonstrated better specificity in SW480 cells than the other promoters tested. In contrast, some intestine-specific promoters, such as HIFABP and HLY, could effectively drive luciferase expression in non-

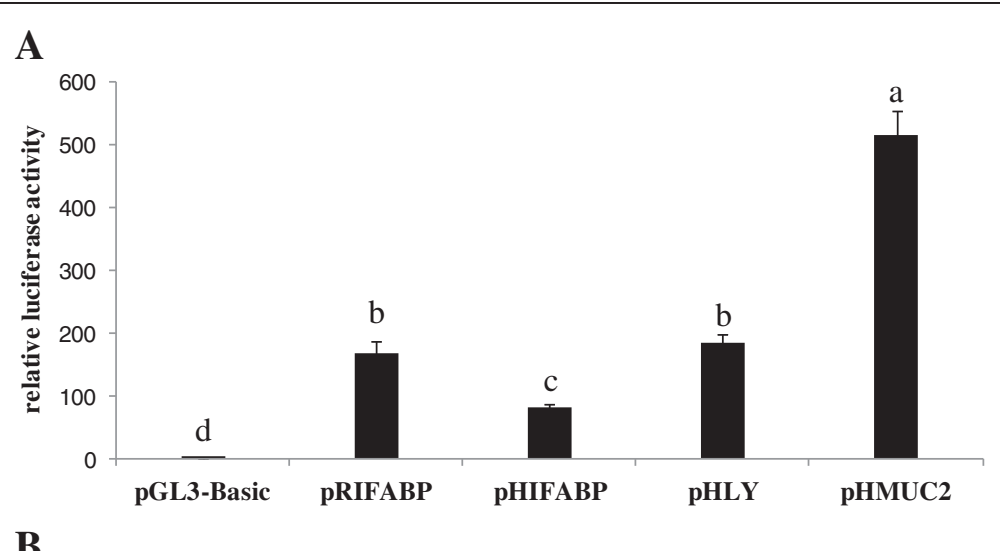

B

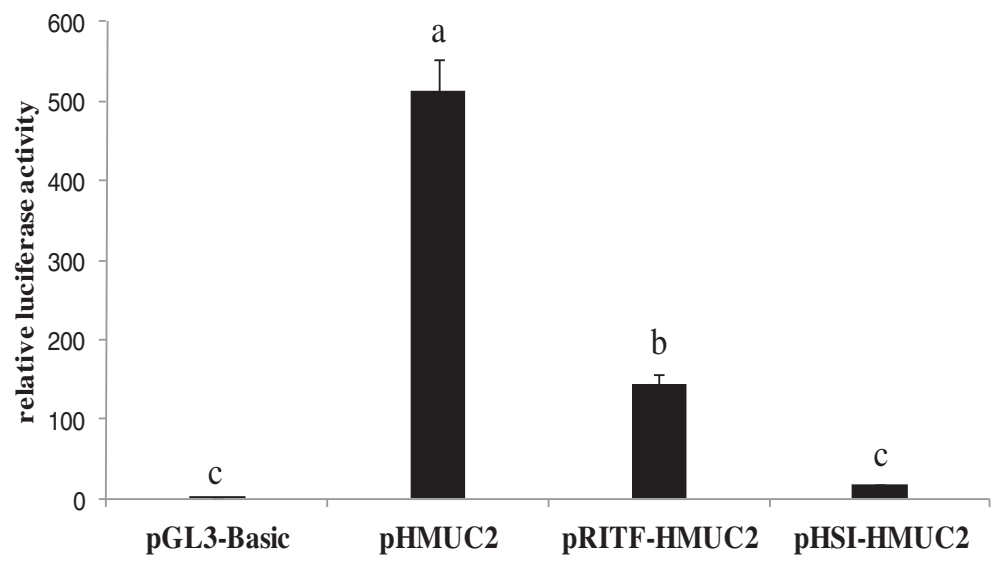

C

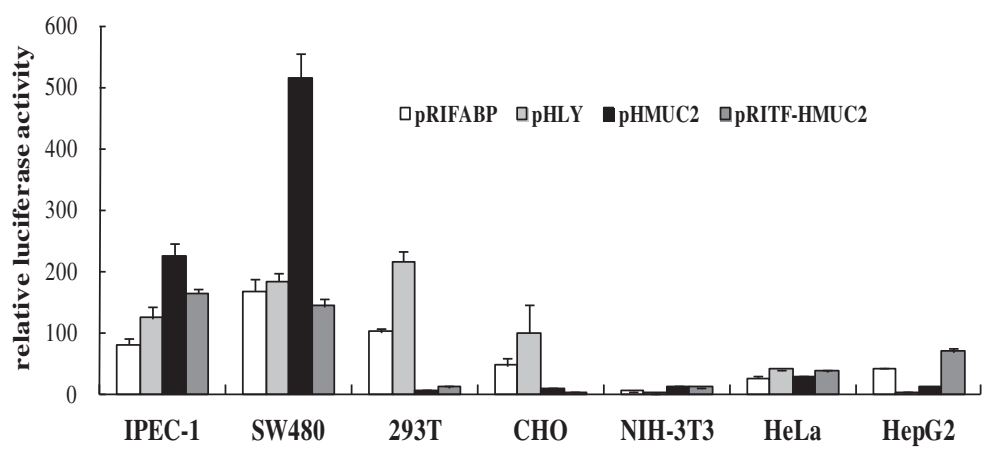

Figure 2 Analysis of the activity and specificity of promoters/enhancers. (A) Luciferase activity from the different intestine-specific promoters was analyzed by transient transfection in SW480 cells. (B) Influence of the HSI and RITF enhancer on human mucin-2 promoter (HMUC2) activity. (C) Luciferase activity of indicated plasmids in intestinal cells (SW480) and non-intestinal cells (CHO, HeLa, NIH-3T3, HepG2 and 293T). Data are presented as the relative activity of Firefly luciferase to Renilla luciferase in order to normalize transfection efficiency among different wells. The means \pm SEM of luciferase expression driven from the selected intestine-specific promoter/enhancers are represented. Different letters represent significant difference, $P<0.01$. 
intestinal cells, especially in $293 \mathrm{~T}$ and $\mathrm{CHO}$ cells (Figure 2C).

\section{Testing functional repressor binding to the lac operator} Regulation of reporter gene expression by the modified lac operon system is shown in Figure 3. Co-transfection of pNLacI and pHMLacO yielded luc activity about 6.5fold lower than with expression of pHMLacO alone $(P<$ $0.05)$. When the inducers IPTG or $\alpha$-lactose were added, luc activity was increased $(P<0.05) 5$-fold and 4.8 -fold, respectively, similar to that for transfection with pHMLacO alone. These results (Figure 3A) indicate that both IPTG and $\alpha$-lactose could bind well to the repressor and therefore eliminate $(P<0.05)$ its inhibitory effect.

In addition, transient transfection with single pHMLacO-GFP resulted in the generation of cells with bright GFP-derived fluorescence (seen in Figure 3B). In contrast, co-transfection of pHMLacO-GFP and pNLacI gave rise to poor fluorescence. When the inducers (IPTG and $\alpha$-lactose) were added, the fluorescence intensity was similar to cells transfected with pHMLacOGFP alone. FACS analysis showed that the percentage of cells transfected with pHMLacO-GFP with GFP expression had a mean of $23.68 \%$, while in SW480 cells transfected with pHMLacO-GFP and pNLacI, it was below $11.68 \%$. The numbers of cells exhibiting high degrees of fluorescence increased to $19.80 \%$ and $20.03 \%$ when IPTG and $\alpha$-lactose were added, respectively.

\section{Determination of a-galactosidase mRNA and protein levels}

Both mRNA levels and enzyme activity of $\alpha$-galactosidase were dramatically decreased $(P<0.05)$ by the introduction of a repressor. When the inducers IPTG and $\alpha$-lactose were added, inhibition of the repressor

A

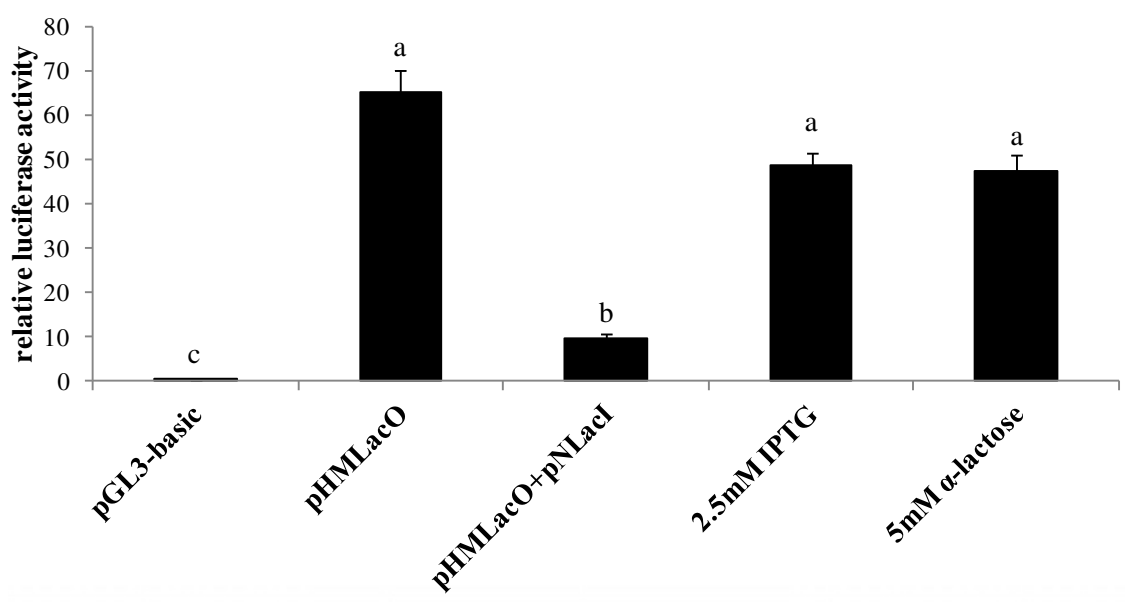

B

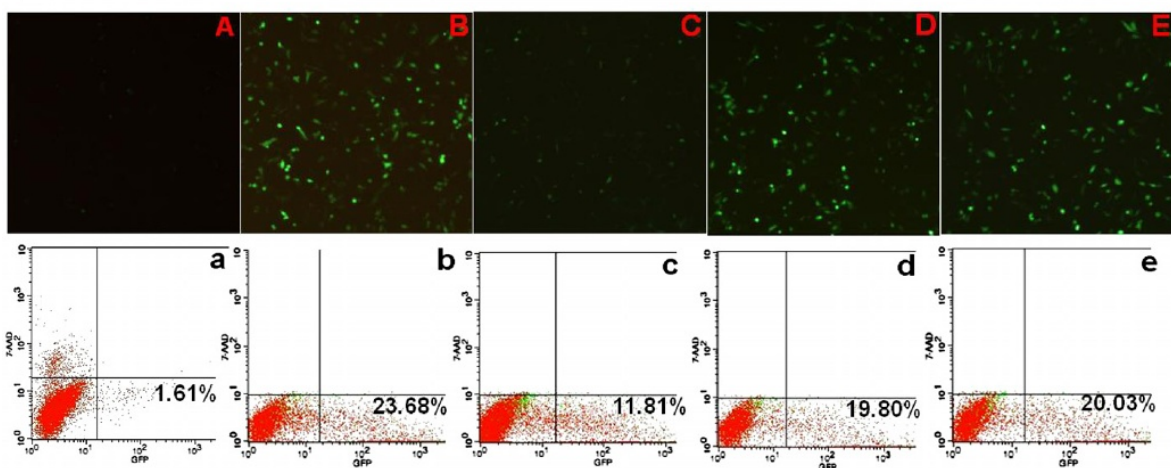

Figure 3 Effects of IPTG and a-lactose on the transient expression of luciferase and green fluorescent protein (GFP) activity after transfection of SW480 cells with luciferase-containing and GFP-containing plasmids, respectively. (A) Effects of inducers on the transient expression of luciferase activity; lysates were derived from SW480 cells transfected with luciferase-containing plasmids and incubated for $48 \mathrm{~h}$ before harvesting. Data are presented as relative activity of Firefly luciferase to Renilla luciferase in order to normalize transfection efficiency among different wells. Different letters represent significant difference, $P<0.05$. (B) Qualitative analysis of inducer effect on transient expression of GFP activity. a-e: FACS analysis of cells transfected with vectors shown (A-E, A:pGL3-basic, B: pHMLacO, C: pNLacl and pHMLacO, D: inducer IPTG, E: inducer a-lactose). The percentage of cells exhibiting strong fluorescence (date marked area) was calculated as the number of cells exhibiting fluorescence. 
was greatly relieved so that both the $\alpha$-galactosidase mRNA levels and enzyme activity were increased $(P<0.05)$ by 5 -fold and 7 -fold, respectively (Figure 4$)$.

\section{Discussion}

Intestine-specific regulatory elements can achieve a maximal expression of candidate genes in the gastrointestinal gut. Previous work has shown that some intestine-specific promoters, such as HIFABP [9], RIFABP [10], HMUC2 [11] and HLY [12], can efficiently activate downstream gene expression in intestinal cells or tissues. However, the promoter conferring the highest activity has not yet been determined. Therefore, we first compared the transcriptional characteristics of these four promoters and found that the HMUC2 promoter had the highest activity in SW480 cells, which was about 2 to 3 times higher than that of the other three promoters. In addition, the HMUC2 promoter had low activity in NIH-3T3, 293T, CHO, HeLa and HepG2 cells. These results are similar to previous work by Gum et al. [11], who found that HMUC2 promoter activity was 4- to 6fold higher in Cla cells than in other cell lines (L cells, AGS, HT-1080 and MGC80-3). Cla cells are a type of intestinal cell; however, HMUC2 promoter activity was not investigated in other typical intestinal cell lines, such as IPEC-1, SW480 or Coco-2. The activity of the HMUC2 promoter being highest in SW480 cells might relate to transcription factors, such as the SP1 family, CDX2 and GATA. Several lines of evidence demonstrate that MUC2 promoter activity is greatly reduced by mutation in the SP1 [25,26] and GATA-4 binding sites [27], while CDX2 binding to the MUC2 gene cis element results in a 5-fold enhancement in activity [28].

The other promoters we tested showed varying degrees of non-specific activity. Rottman and Gordon [29] reported that the RIFABP promoter has high activity in the Caco-2 cell line but still activates gene expression in HeLa and HepG2 cell lines, which was consistent
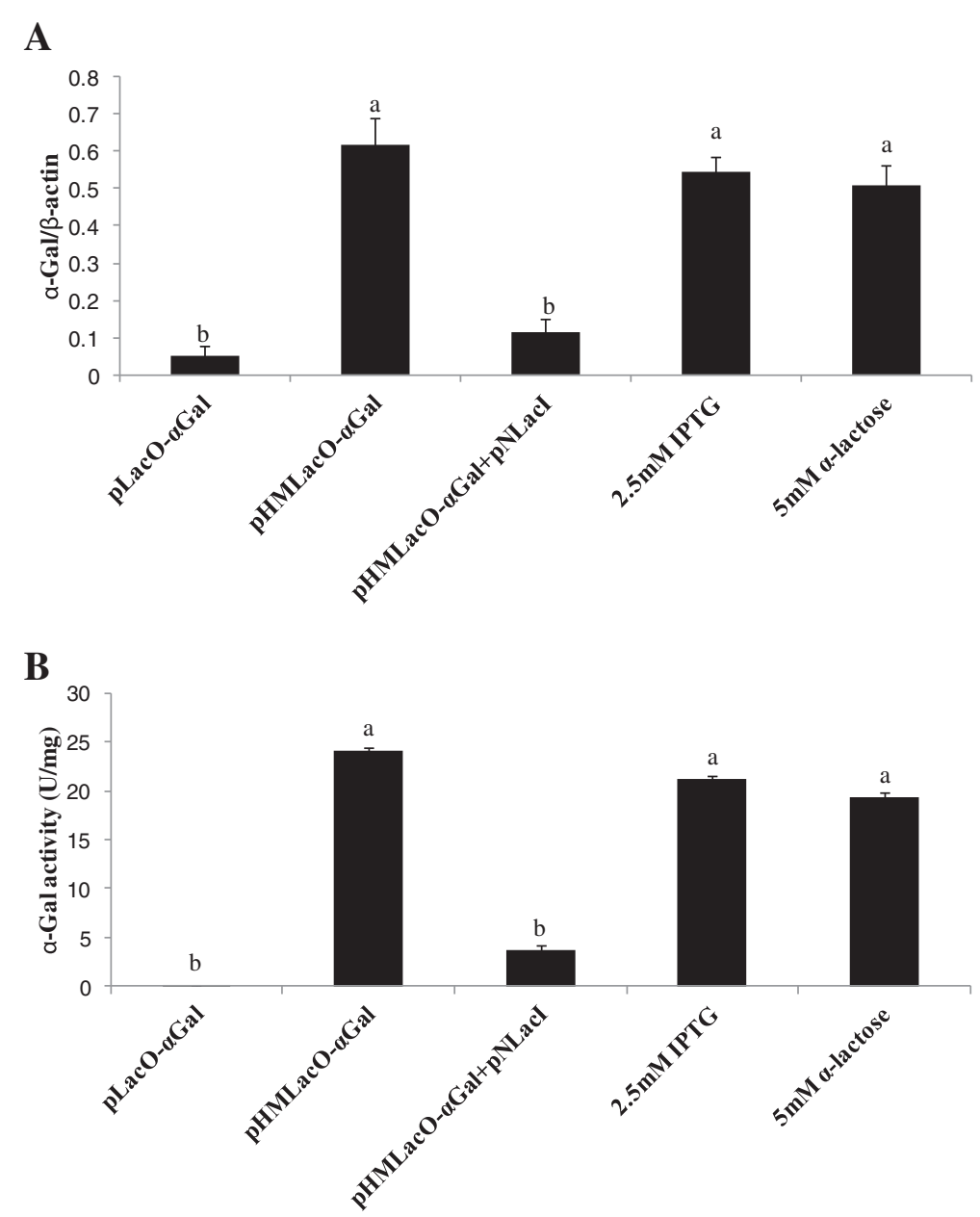

Figure 4 Effects of inducers on the transient expression of a-galactosidase (a-Gal) mRNA and on a-Gal activity levels. (A) RT-PCR analysis of a-Gal mRNA levels; $\beta$-actin was used to control transfection efficiency and cell recovery. (B) a-Gal activity assay. Values are the average of triple determinations with the SD indicated by error bars. Different letters represent significant difference, $P<0.01$. 
with our results. Paneth cells of the small intestine are a rich source of lysozyme (encoded by $H L Y$ ) [30], although the HLY promoter has low activity in the small intestine and can be detected in both HepG2 and U937 cell lines. In addition, in vivo experiments also support the conclusion that HLY promoter activity in the small intestine is only about $5 \%$ of that in the lungs in transgenic mice [12]. Hence, compared with IFABP and HLY promoters, the HMUC2 promoter might be the most appropriate regulatory element for intestine-specific gene expression.

To increase the strength of the intestine-specific promoters, we produced a series of chimeric sequences by combining the HMUC2 promoter with enhancers from the HSI and RITF genes. The HSI enhancer contains three nuclear protein-binding sites; SIF indicates the SI (sucrase-isomaltase enhancer) footprint ,stands for western blot.. SIF1 is responsible for intestine-specific SI transcription and can act as an enhancer for the SI promoter [31]. SIF2 and SIF3 bind hepatocyte nuclear factor (HNF-1 $\alpha$ and HNF-1 $\beta$ ) [32] The RITF enhancer, containing a 9 base pair (CCCCTCCCC) element between -154 and -118 in the RITF promoter, is a cis-active element bound by a distinct nuclear transcription factor and is capable of increasing promoter activity [14]. We fused the RITF and HSI enhancers with the HMUC2 promoter, to generate a promoter predicted to have strong intestine-specific activity. However, the opposite results were observed; HMUC2 promoter activity was decreased 3-fold and 30-fold by the RITF and HSI enhancers, respectively. This result may be explained by promoter specificity and the location and orientation of a non-classical enhancer. Troelsen et al. [33] found that the intestinal lactase phlorizin hydrolase (LPH) enhancer is only active in front of intestine-specific promoters, such as LPH and SI promoters, but not the SV40 promoter. It is worth noting that the LPH enhancer could inhibit SI promoter activity irrespective of location and orientation. Thus, the effects of location and orientation of the HSI and RITF enhancers on the activity of intestine-specific promoters still needs further study.

Inducible systems that incorporate cell-specific promoters enable a target gene to be switched on and off repeatedly when needed without affecting the expression of non-targeted genes. In recent years, binary systems based on the interaction of two components, such as the lac operon system [15], the tetR-based system [16], the GAL4-based system [17] and the Cre/loxP recombination system [18] have been used to turn gene expression on and off. The VP16-activating domain in the TetRbased system and the GAL4-based system has been found to be toxic to cells [16]. The Cre/loxP system had been widely used in gene activation with non-reversible effects, while the lac operon system has successfully used mammalian regulatory elements to control gene expression in mammalian cells and transgenic mice for some time [15,19]. Most importantly, $\alpha$-galactosidase gene expression based on the lac operon system could be increased along with the production of $\alpha$-lactose because $\alpha$-lactose is both the inducer of the lac operon system and the substrate of $\alpha$-galactosidase. Therefore, we constructed a modified lac operon system consisting of two important components: the 116-bp operator and the repressor with a nuclear localization signal (NLS) added before the termination codon (TAG). In the lac operon system, luc activity and the percentage of cells with GFP expression were decreased 6.5-fold and 2-fold, and the $\alpha$-galactosidase mRNA level and $\alpha$-galactosidase activity were reduced 6 -fold and 8-fold, respectively, due to inhibition by the repressor, which could be relieved when IPTG or $\alpha$-lactose was added. These results were similar to those of previous studies [34].

We also found that the lac operon had a low-level leakiness; the target gene was still expressed at a low level when the repressor bound to the lac operator. This phenomenon was also investigated by Wyborski and DuCoeur, although they had successfully used the lac operon to regulate gene expression in vivo [20]. The $\mathrm{LacO}$ inserted at both -10 and -35 led to promoter activity being decreased 45-fold in the presence of a repressor [19]. In addition, the specificity of the repressor-operator interaction can be further increased by introducing a small degree of asymmetry in the operator; the symmetry in the operator alters the translational efficiency, but it cannot affect transcription [35]. We observed that $\alpha$ galactosidase mRNA and protein levels have a similar trend, shown in Figure 4, which suggested that the location rather than the symmetry of the operator in the HMUC2 promoter should be changed to reduce the lowlevel leakiness. Re-encoding or mutating some amino acids in the lacI sequence can significantly improve suppression capability, as has been successfully shown by Mueller-Hartmann and Mueller-Hill [36]. Thus, the problem of low-level leakiness can be overcome in future work by altering the location of $\mathrm{LacO}$ and by introducing appropriate mutations into the LacI sequence.

$\alpha$-galactosidase has drawn much attention due to its wide use in Fabry disease therapy and in feed additives to increase nutrition utilization efficiency and animal growth [4-6].

Although human $\alpha$-galactosidase has been successfully applied in transgenic mice [1,7], it is uncertain whether bacterial $\alpha$-galactosidase can be expressed in mammalian cells and transgenic animals. Some evidence reports that bacterial genes introduced into the mammalian genome are difficult to express due to methylation [37]. However, bacterial xylanase has been successfully used in transgenic mice, and activity of the enzyme can be detected up to $4.2 \mathrm{U} / \mathrm{mg}$ [38]. Our present results indicate that 
bacterial $\alpha$-galactosidase can also be successfully expressed in mammalian cells and that $\alpha$-galactosidase activity could be measured at about $24 \mathrm{U} / \mathrm{mg}$. Several in vivo studies have shown that $\alpha$-galactosidase supplementation with $0.08 \mathrm{U} / \mathrm{kg}$ feed in growing pig diets containing soybean meal and with $2.3 \mathrm{U} / \mathrm{kg}$ feed in piglet diets could significantly improve Gain:Feed by $6 \%$ and increase the digestibility of carbohydrates and protein in the small and large intestine $[39,40]$. Therefore, our inducible and highly-efficient $\alpha$-galactosidase expression system might provide the basis for further transgenic pig production. The intestine-specific inducible system could also be beneficial for studying the function and effect of other exogenous genes in transgenic animals.

\section{Competing interests}

The authors declare that they have no competing interests.

\section{Authors' contributions}

ZYF participated in the design of the study, carried out the experiments, statistical analysis and wrote the first draft of the manuscript. SG participated in the design of the study and the statistical analysis, and oversaw manuscript preparation. ZXT and ZZQ participated in the cell experiments and plasmid construction. WSB, WLN, ZYL and JQY participated in study design and coordination. LXJ participated in writing the final versions of the manuscript. All authors have read and approved the final manuscript.

\section{Acknowledgements}

We would like to thank Prof. Yao (Feed Research Institute Chinese Academy of Agricultural Sciences, China) for providing the pPIC9-Agil vector. This work was supported by the National Key Project (2009CB941601, 2008ZX08006004 and 2009ZX0890-024B) and the Joint Funds of the National Natural Science Foundation of China (u0731004).

Received: 28 April 2012 Accepted: 15 October 2012

Published: 30 October 2012

\section{References}

1. Ohashi T, lizuka S, Ida H, Eto Y: Reduced alpha-Gal A enzyme activity in Fabry fibroblast cells and Fabry mice tissues induced by serum from antibody positive patients with Fabry disease. Mol Genet Metab 2008, 94:313-318.

2. Lenny LL, Hurst R, Goldstein J, Galbraith RA: Transfusions to group $O$ subjects of 2 units of red cells enzymatically converted from group $B$ to group O. Transfusion 1994, 34:209-214.

3. Leske $\mathrm{KL}$, Coon $\mathrm{CN}$ : Hydrogen gas production of broiler chicks in response to soybean meal and alpha-galactoside free, ethanol-extracted soybean meal. Poultry Sci 1999, 78:1313-1316.

4. Igbasan FA, Guenter W, Slominski BA: The effect of pectinase and alphagalactosidase supplementation on the nutritive value of peas for broiler chickens. Can J Anim Sci 1997, 77:537-539.

5. Waldroup PW, Keen CA, Yan F, Zhang K: The effect of levels of alphagalactosidase enzyme on performance of broilers fed diets based on corn and soybean meal. J Appl Poultry Res 2006, 15:48-57.

6. Ghazi S, Rooke JA, Galbraith $\mathrm{H}$ : Improvement of the nutritive value of soybean meal by protease and alpha-galactosidase treatment in broiler cockerels and broiler chicks. Brit Poultry Sci 2003, 44:410-418.

7. Ishii S, Yoshioka H, Mannen K, Kulkarni AB, Fan JQ: Transgenic mouse expressing human mutant a-galactosidase $A$ in an endogenous enzyme deficient background: a biochemical animal model for studying activesite specific chaperone therapy for Fabry disease. Bba-Mol Basis Dis 2004, 1690:250-257.

8. Horn C, Wimmer EA: A transgene-based, embryo-specific lethality system for insect pest management. Nat Biotechnol 2003, 21:64-70.

9. Klapper M, Boehme M, Nitz I, Doering F: The human intestinal fatty acid binding protein (hFABP2) gene is regulated by HNF-4 alpha. Biochem Bioph Res Co 2007, 356:147-152.
10. Sweetser DA, Hauft SM, Hoppe PC, Birkenmeier EH, Gordon Jl: Transgenic mice containing intestinal fatty acid-binding protein-human growth hormone fusion genes exhibit correct regional and cell-specific expression of the reporter gene in their small intestine. P Natl Acad Sci USA 1988, 85:9611-9615.

11. Gum JR Jr, Hicks JW, Toribara NW, Siddiki B, Kim YS: Molecular Cloning of Human Intestinal Mucin (MUC2) CDNA: Identification of the amino terminus and overall sequence similarity to prepro-Von Willebrand factor. J Biol Chem 1994, 269:2440-2446.

12. Clarke S, Greaves DR, Chung L-P, Tree P, Gordon S: The human lysozyme promoter directs reporter gene expression to activated myelomonocytic cells in transgenic mice. P Natl Acad Sci USA 1996, 93:1434-1438.

13. Wu GD, Wang W, Traber PG: Isolation and characterization of the human sucrase-isomaltase gene and demonstration of intestine-specific transcriptional elements. J Biol Chem 1992, 267:7863-7870.

14. Ogata $H$, Inoue N, Podolsky DK: Identification of a goblet cell-specific enhancer element in the rat intestinal trefoil factor gene promoter bound by a goblet cell nuclear protein. J Biol Chem 1998, 273:3060-3067.

15. Cronin CA, Gluba W, Scrable H: The lac operator-repressor system is functional in the mouse. Gene Dev 2001, 15:1506-1517.

16. Baron U, Gossen M, Bujard H: Tetracycline-controlled transcription in eukaryotes: novel transactivators with graded transactivation potential. Nucleic Acids Res 1997, 25:2723-2729.

17. Ornitz DM, Moreadith RW, Leder P: Binary system for regulating transgene expression in mice: targeting int-2 gene expression with yeast GAL4/ UAS control elements. P Natl Acad SCI 1991, 88:698.

18. Gu H, Zou YR, Rajewsky K: Independent control of immunoglobulin switch recombination at individual switch regions evidenced through Cre-loxP-mediated gene targeting. Cell 1993, 73:1155.

19. Hu MC, Davidson N: The inducible lac operator-repressor system is functional in mammalian cells. Cell 1987, 48:555-566.

20. Wyborski DL, DuCoeur LC, Short JM: Parameters affecting the use of the lac repressor system in eukaryotic cells and transgenic animals. Environ Mol Mutagen 1996, 28:447-458.

21. Scrable H, Stambrook PJ: Activation of the lac repressor in the transgenic mouse. Genet 1997, 147:297-304.

22. Oehler $\mathrm{S}$, Eismann ER, Kramer H, Muller-Hill B: The three operators of the lac operon cooperate in repression. EMBO J 1990, 9:973-979.

23. Oehler $\mathrm{S}$, Amouyal $\mathrm{M}$, Kolkhof $\mathrm{P}$, Wilcken-Bergmann BV, Mueller-Hill B: Quality and position of the three lac operators of E. coli define efficiency of repression. EMBO J 1994, 13:3348-3355.

24. den Herder IF, Rosell AM, van Zuilen CM, Punt PJ, van den Hondel CA: Cloning and expression of a member of the Aspergillus niger gene family encoding alpha-galactosidase. Mol Gen Genet 1992, 233:404-410.

25. Nogami H, Ohmori H, Li JD, Gallup M, Gum J, Kim Y, Basbaum C: Sp1 protein contributes to airway-specific rat $<\mathrm{i}>\mathrm{MUC} 2</ \mathrm{i}>$ mucin gene transcription. Gene 1997, 198:191-201.

26. Aslam F, Palumbo L, Augenlicht LH, Velcich A: The Sp family of transcription factors in the regulation of the human and mouse MUC2 gene promoters. Cancer Res 2001, 61:570.

27. van der Sluis M, Melis MHM, Jonckheere N, Ducourouble MP, Büller HA, Renes I, Einerhand AWC, Van Seuningen I: The murine Muc2 mucin gene is transcriptionally regulated by the zinc-finger GATA-4 transcription factor in intestinal cells. Biochem Bioph Res Co 2004, 325:952-960.

28. Yamamoto $H, B a i Y Q$, Yuasa $Y$ : Homeodomain protein $C D X 2$ regulates goblet-specific MUC2 gene expression. Biochem Bioph Res Co 2003, 300:813-818.

29. Rottman JN, Gordon Jl: Comparison of the patterns of expression of rat intestinal fatty acid binding protein/human growth hormone fusion genes in cultured intestinal epithelial cell lines and in the gut epithelium of transgenic mice. J Biol Chem 1993, 268:11994-12002.

30. Keshav S, Chung P, Milon G, Gordon S: Lysozyme is an inducible marker of macrophage activation in murine tissues as demonstrated by in situ hybridization. J Exp Med 1991, 174:1049.

31. Rodolosse A, Chantret I, Lacasa M, Chevalier G, Zweibaum A, Swallow D, Rousset M: A limited upstream region of the human sucrase-isomaltase gene confers glucose-regulated expression on a heterologous gene. Biochem J 1996, 315:301-306.

32. Rodolosse A, Carriere V, Rousset M, Lacasa M: Two HNF-1 binding sites govern the glucose repression of the human sucrase-isomaltase promoter. Biochem J 1998, 336:115-123. 
33. Troelsen JT, Mitchelmore C, Olsen J: An enhancer activates the pig lactase phlorizin hydrolase promoter in intestinal cells. Gene 2003, 305:101-111.

34. Daber R, Lewis M: Towards evolving a better repressor. Protein Eng Des Sel 2009, 22:673-683.

35. Daber R, Lewis M: A Novel Molecular Switch. J Mol Biol 2009, 391:661-670.

36. Müller-Hartmann H, Müller-Hill B: The side-chain of the amino acid residue in position 110 of the Lac repressor influences its allosteric equilibrium. $J$ Mol Biol 1996, 257:473-478.

37. Nilsson $E$, Lendahl U: Transient expression of a human $\beta$--actin promoter/ lacZ gene introduced into mouse embryos correlates with a low degree of methylation. Mol Reprod Dev 1993, 34:149-157.

38. Fontes CMGA, Ali S, Gilbert HJ, Hazlewood GP, Hirst BH, Hall J: Bacterial xylanase expression in mammalian cells and transgenic mice. J Biotechnol 1999, 72:95-101.

39. Gdala J, Johansen HN, Bach Knudsen KE, Knap IH, Wagner P, Jørgensen O: The digestibility of carbohydrates, protein and fat in the small and large intestine of piglets fed non-supplemented and enzyme supplemented diets. Anim Feed Sci Tech 1997, 65:15-33.

40. Baucells F, Pérez J, Morales J, Gasa J: Effect of alpha-galactosidase supplementation of cereal-soya-bean-pea diets on the productive performances, digestibility and lower gut fermentation in growing and finishing pigs. J Anim Sci 2000, 71:157-164.

doi:10.1186/2049-1891-3-32

Cite this article as: Zhai et al.: Identification of an intestine-specific promoter and inducible expression of bacterial a-galactosidase in mammalian cells by a lac operon system. Journal of Animal Science and Biotechnology 2012 3:32.

\section{Submit your next manuscript to BioMed Central and take full advantage of:}

- Convenient online submission

- Thorough peer review

- No space constraints or color figure charges

- Immediate publication on acceptance

- Inclusion in PubMed, CAS, Scopus and Google Scholar

- Research which is freely available for redistribution 